\title{
EL ORDENAMIENTO JURÍDICO ESPAÑOL ANTE LA VIOLENCIA DE GÉNERO.
}

\section{OLGA FUENTES SORIANO}

Profesora Titular de Derecho Procesal. Centro de Estudios de la Mujer. Universidad de Alicante.

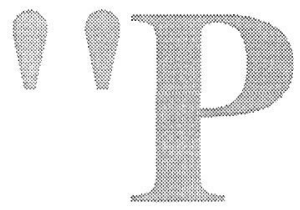

aulina Cancino no sabe, como muchas otras de sus compañeras, cuantos años hace que nació, calcula que pueden ser más o menos veintisiete o veintiocho. Pero sí sabe que su madre sepultó su cordón umbilical bajo las cenizas del fogón, sellando así metafóricamente su destino; no en vano el cordón de su hermano fue llevado al monte y enterrado bajo la libertad de la naturaleza pura. Nació sabiendo que, a su contrario, ella nunca podría ser dueña de la tierra que trabajara, nunca obtendría un título de propiedad ni un préstamo, que no podría aspirar a un cargo de autoridad y que si alguna vez sufría la tragedia de ser violada, el violador pasaría a ser su dueño y señor (...). Tampoco está segura de la cantidad de hermanos que tiene, cree que son nueve. Sí está cierta del lugar que ella ocupa, el tercero, todas mujeres, y que su padre festejó la mano de obra que llegaba a casa cuando el cuarto fue hombre. (...) Sentía a su madre levantarse a las tres de la mañana para hacer tortillas y dejar la comida preparada. Su padre salía al amanecer montado en su caballo. Su madre lo seguía a pie, cargando al menor de sus hermanos, los otros quedaban a cargo de las hermanas mayores, cualquier edad tuviesen éstas. Su madre lavaba la ropa de noche porque no tenía tiempo en el día, Paulina nunca la vio dormir más de cuatro horas. Su papá descansaba en la tarde del trabajo en el campo, pero ella había trabajado con él, igual que él, con el azadón y el machete en la milpa. Además cuidaba a los hijos, cocinaba, hacía tortillas, remendaba los vestidos y adecentaba la casa. Trabajaba mucho más que él. Aun así, cuando él había bebido mucho aguardiente, llegaba a casa y la golpeaba, a veces brutalmente. Paulina fue preparada desde siempre para ser madre. Pero también, junto con nacer, le enseñaron a ir a la milpa, a moler el maíz, a cortar la leña, a recoger el café, a cargar al bebé. Paulina trabajaba desde que fue. (...) Cuando nació el cuarto hijo y fue varón, además del festejo del padre, la madre respiró, ya estaba a salvo, pues la tierra era la médula de sus vidas y la mujer no tiene derecho a ella. Si enviuda o queda soltera no come. Cuando su hermana mayor tenía trece años le concertaron el matrimo- 
nio. Sus padres le eligieron al marido y éste les llevóregalos: maíz, frijol un poco de tela y unos aretes. No alcanzó para una vaca. (...) Pero su hermana no dijo nada. Se fue a la casa de él para que su suegra le enseñara entregándole de paso casi todos los trabajos domésticos, en franca explotación. Paulina recuerda cómo la compadecía cuando en las fiestas no podía bailar, primero por estar comprometida, luego por estar casada. Ella sí podía bailar, aunque jamás tocara ni mirara a su acompañante, simplemente porque era un hombre: estaba prohibido. Su hermana vivió tres años con sus suegros y no se embarazó. Entonces su cuñado armó una casa separada de la de sus padres para recibir a los futuros hijos, pero éstos no llegaron. La segunda hermana se fue a vivir con ellos. Como el que mantiene a una mujer en la comunidad tiene derecho a ella, al poco tiempo apareció la última embarazada, llenando de deleite al hombre cuya seguridad dependía de ello. Es muy bien visto para el macho tener hijos, dice Paulina hoy día. Y para las hermanas, un seguro de vida. Además, si la primera mujer no le dio descendencia, resultaba legítimo que lo hiciese la segunda, y así convivían los tres, naturalmente. Como una demencia habría sido calificado el que la hermana mayor se separara. En su comunidad casi no existen las separaciones, las mujeres no tienen dónde ir, la falta de movilidad y los serios problemas económicos las atan al marido para siempre. La última vez que Paulina vio a sus hermanas ya habían llegado cinco críos a la casa. A los treinta años, las mujeres indígenas son unas ancianas y acarrean los cuerpos viejos, dice Paulina hoy día. El promedio de hijos es de siete; algunas de sus parientas tenían doce. La primera vez que Paulina oyó hablar de planificación familiar fue con la llegada de los zapatistas. Pero la Iglesia católica les recordó, una vez más, que aquello era pecado. Paulina se pregunta en qué número irán estos días". ${ }^{1}$

La razón por la que se han extractado los párrafos anteriores de la obra de Marcela Serrano, Lo que está en mi corazón, reside, como fácilmente se puede comprobar, en el excelente reflejo que suponen de las condiciones que originan la violencia por razón de género. Si bien es cierto que el contexto en el que se recrea la descripción se circunscribe a las comunidades indígenas mexicanas, se trata del reflejo de una estructura social que en mayor o menor medida y en mayor o menor distancia temporal con la actualidad, todos podemos reconocer como vertebradora de nuestra realidad social. No en vano, el concepto de género, como categoría analítica acuñada por el feminismo de los años 70 hace referencia al conjunto de pautas culturales, sociales, religiosas... -no biológicas- que sitúan a las mujeres, por el hecho de serlo, en una posición de inferioridad en relación con los hombres.

Los elementos determinantes de la violencia de género son muchos

1 SERRANO, M.: Lo que está en mi corazón, Ed. Plantea, Barcelona 2001, pp. 157-160. 
y muy variados y, curiosamente, vienen a coincidir con los pilares o los ejes estructurales de la sociedad. De entre todos ellos, sin lugar a dudas, podrían destacarse los siguientes:

- Elementos culturales (entre los que cabe incluir el determinante factor religioso). En este sentido, existen determinadas costumbres sociales (como, en el caso de los párrafos extractados, la imposibilidad de bailar o, en su caso, la imposibilidad de tocar o mirar al varón), determinados principios culturales o normas religiosas que predican una situación de absoluta sumisión de la mujer en relación con el hombre (piénsese en los evangelios cristianos del matrimonio y la concepción de la mujer "como parra fecunda" o en el rol atribuido a la mujer en religiones de mayor fundamentalismo como la islámica).

- Elementos educacionales. En este sentido conviene destacar la distribución de roles, perfectamente reflejada también en los párrafos anteriores, a tenor de los cuales a la mujer, desde que nace, le espera el trabajo doméstico y "la colaboración" en determinadas tareas propias del marido. Aún cuando esta situación, en nuestra actual sociedad occidental, pueda resultar algo lejana, es cierto que no somos sino herederos de ella y que la adjudicación a la mujer del ingrato e impagado trabajo doméstico es fuente de insatisfacción, por una parte, y de dependencia económica del marido, por otra.

- Elementos jurídicos. En el caso del Derecho asistimos a una curiosa paradoja, pues si bien es cierto que el Derecho, por una parte, es elemento de estructuración de la sociedad y de la convivencia, es igualmente cierto, por otra parte, que las normas jurídicas van siempre por detrás de la realidad social. En este sentido, téngase presente que hasta que no surge un conflicto-o, al menos, no se prevé la posibilidad de que dicho conflicto surja- no se crea la norma jurídica que lo regule. En consonancia con ello: hasta que no surgen los problemas de violencia de género, no surgen las normas que regulan el comportamiento del Estado frente a dichos problemas. Y, conjuntamente con ello, debe tenerse igualmente presente que el Derecho, precisamente por ser el elemento regulador y estructurador de la sociedad y la convivencia, reconoce y consagra implícita e incluso en ocasiones, explícitamente, patrones machistas o de dominio del varón sobre la mujer. Hasta fechas relativamente recientes, el ordenamiento jurídico español contaba con normas tales como la incapacidad de contratar de la mujer casada, o la obligación de ésta de fijar su residencia allá donde el marido la fijara, o la tipificación de determinados delitos, como el adulterio, exclusivamente para la mujer. Como es fácil imaginar, todo ello lleva a la consagración legal de la posición real de dominio del varón sobre la vida de la mujer. 
En términos globales es posible afirmar que la estructuración de la convivencia sobre la base de un patrón androcéntrico es elemento común a las diferentes culturas y sociedade ${ }^{2} y$, en este sentido la violencia de género no es más que una consecuencia: quienes históricamente han detentado el poder sin más justificación que su pertenencia al sexo masculino, han esgrimido sus armas contra quienes, también injustificadamente, carecían del mismo por su mera pertenencia al sexo femenino. ${ }^{3}$

La crudeza con la que se presenta el problema de la violencia de género a nivel internacional ha ocasionado, a partir de la segunda mitad del siglo XX, una importante proliferación de instrumentos legislativos emanados fundamentalmente de NU y en defensa del derecho a la igualdad entre hombres y mujeres. ${ }^{4}$ En este sentido, la Declaración de Naciones Unidas sobre la eliminación de la violencia contra la mujer (diciembre 1993) entiende que dicha violencia abarca: ${ }^{5}$

2 "Es así como el principio patriarcal [sostiene PÉREZ DEL CAMPO] se ha insertado en nuestro sistema de creencias, dándoselo por indiscutible y legitimado desde todos los ángulos y puntos de vista, la ley, la política, la ciencia, la religión han contribuido eficazmente a ello; de tal suerte que la mujer, por el simple hecho de serlo se viera impedida de desarrollar las capacidades que como persona le correspondían". PÉREZ DEL CAMPO, A.M., "Recursos para la recuperación integral de las víctimas de la violencia de género" en Primeras jornadas sobre violencia de género. Aspectos Técnicos y judiciales, Ajuntament de Sant Joan d'Alacant, Mayo 2001, pp. 23 a 52; p. cit. 25.

3 Ante una situación como la expuesta, cobra pleno sentido la descripción de la discriminación realizada por el art. 1 de la "Convención sobre la eliminación de todas las formas de discriminación contra la mujer" (adoptada por Naciones Unidas mediante la Resolución de la Asamblea General de la ONU N ${ }^{\circ} 34 / 180$ ). A tenor de dicho precepto, la discriminación supone "toda distinción, exclusión o restricción basada en el sexo que tenga por objeto o por resultado menoscabar o anular el reconocimiento, goce o ejercicio por la mujer, independientemente de su estado civil, sobre la base de igualdad del hombre y la mujer, de los derechos humanos y las libertades fundamentales en las esferas política, económica, social, cultural y civil o en cualquier otra esfera".

4 Un breve recorrido por este panorama legislativo puede verse en Guía de buenas prácticas y usos forenses para combatir la violencia de género, Asociación de mujeres juristas Themis, 2001.

5 Vid. en parecido sentido, la fundamentación del documento base para la elaboración de una propuesta de Directiva sobre la violencia contra las mujeres y la infancia elaborada en el seno de la Conferencia Europea en materia de violencia contra Ias mujeres y la infancia y celebrada en Calviá $(28,29$ y 30 de abril de 2000). En él, los problemas originados por la violencia de género se reconducen a los siguientes cuatro ámbitos: 1) en el ámbito doméstico cuando las relaciones privadas y familiares se ven afectadas por actitudes y actos violentos contra las mujeres, 2) en el ámbito del trabajo producida a través de conductas de acoso sexual, 3) violencia de género ejercida mediante la compraventa de seres humanos con fines de prostitución sexual forzada directa o indirectamente y 4) situación de especial vulnerabilidad en la que se encuentran las mujeres migrantes o refugiadas. 
A) La violencia (física, sexual y psicológica) producida en la familia, incluyéndose aquí no sólo los malos tratos sino también la violencia relacionada con la dote, la mutilación genital femenina o la violencia relacionada con la explotación.

B) La violencia (física, sexual y psicológica) perpetrada dentro de la comunidad en general, incluyéndose aquí las agresiones sexuales, el acoso o la intimidación sexual en el ámbito laboral, la trata de mujeres y la prostitución forzada.

C) La violencia (física, sexual o psicológica) tolerada por el Estado.

De los tres tipos de violencia expresados por UN entiendo que el tercero es, sin duda el más grave y, posiblemente, el más difícil de solucionar, pues, en el fondo, no hace sino aglutinar a los otros dos. Recuérdese la situación paradójica anteriormente comentada en relación con las normas jurídicas y piénsese que cuando el Estado -las leyes- tolera algún tipo de violencia ("el Estado democrático" se entiende) es porque ésta se encuentra íntimamente enraizada en el pensamiento y el sentir social y, en ese contexto, el ordenamiento jurídico no es más que el reflejo, explícitamente manifestado, de dichos sentimientos. En consonancia con lo anterior, el Estado sólo comenzará a dejar de tolerar tal violencia cuando comiencen a cambiar los esquemas estructuradores de la convivencia en sociedad. Es pues, de los tres tipos de violencia, la que jurídicamente encontrará solución en último lugar.

El segundo de los tipos de violencia descritos (violencia física, sexual y psicológica perpetrada dentro de la comunidad en general, incluyéndose aquí las agresiones sexuales, el acoso...) ha sido objeto de importantes reformas legales en los -aproximadamente- veinte últimos años.

Una de las reformas de mayor trascendencia se produjo en 1989 , cuando los hasta entonces denominados "delitos contra el honor" pasaron a denominarse "delitos contra la libertad sexual". ${ }^{6}$ Este cambio legislativo que, a primera vista, pudiera parecer simbólico supone un cambio de actitud y de mentalidad de gran trascendencia que abre una puerta determinante en el éxito de la persecución de los delitos de naturaleza sexual. Si se entiende, como hasta hace unos años, que el bien jurídico protegido por estos tipos penales viene constituido por el honor, se está asumiendo, obviamente, que la perpetración de estos

6 Dicha evolución se produjo con la Ley Orgánica 3/1989, de 21 de junio (art. 17), que modificó la rúbrica del Título IX del entonces vigente Código Penal ("De los delitos contra el honor") pasando a denominarse, por primera vez, "De los delitos contra la libertad sexual". Ésta es la denominación que se mantiene en el Código Penal actual (aprobado en el año 1995) para hacer referencia a los delitos de naturaleza sexual contemplados, todos ellos, en el Título VIII de dicho texto legal. 
delitos lesiona el honor de la víctima. Es decir, que la mujer violada ha sido deshonrada. La reacción primaria frente al deshonor es la tendencia a ocultar el mismo y, como consecuencia, la mujer agredida sexualmente tiende a no denunciar la violación a fin de evitar el público conocimiento de su deshonra. ${ }^{7}$ Esta situación llevaba a la absoluta impunidad del agresor que sabía que, ante la comisión del delito, no iba a haber persecución legal contra él.

A un panorama como el descrito había que sumar el hecho de que, hasta 1999 , los delitos sexuales eran delitos de carácter semipúblico ${ }^{8} \mathrm{y}$, por tanto, sólo podían ser perseguidos previa denuncia de la víctima. La gravedad de esta regulación residía en que aunque se conociera por parte del Estado (de los jueces, fiscales, policía...) la comisión de un hecho delictivo de naturaleza sexual, éste no podía ser perseguido a menos que la víctima del mismo interpusiera la correspondiente denuncia; $y$, como se ha visto, las víctimas eran sumamente reacias a hacer público el padecimiento de una violación. De nuevo la legislación garantizaba la impunidad del delincuente. Esta situación cambia a raíz de una importante reforma legislativa producida en el año $1999^{9} \mathrm{y}$, a tenor de la cual, el Ministerio Fiscal podrá, a iniciativa propia y previa ponderación de los intereses en conflicto, perseguir criminalmente la comisión de delitos sexuales independientemente de la interposición o no de denuncia por parte de la víctima (art. 191.1 del Código Penal). ${ }^{10}$

7 Este tema ha sido tratado con mayor detenimiento en FUENTES SORIANO, O., "La valoración de la prueba indiciaria y la declaración de la víctima en los delitos sexuales", Problemas actuales de la administración de justicia en los delitos sexuales, Defensoría del Pueblo, Perú, Lima, 2000, pp. 151 a 194.

8 En nuestro ordenamiento jurídico se distingue entre delitos públicos, semipúblicos y privados. Los delitos públicos son aquéllos perseguibles de oficio por el Estado sin necesidad de que la víctima muestre su voluntad de perseguirlos; constituyen la regla general -piénsese que es obligación del Estado garantizar la paz social independientemente de cuál sea la voluntad de las víctimas- y entre ellos podemos encontrar los robos, hurtos, lesiones, homicidios o asesinatos, estafas, etc. Los delitos semipúblicos requieren para su persecución por el Estado que la víctima de los mismos denuncie los hechos; una vez denunciados, el Estado persigue al delincuente y sostiene la acusación en juicio a través de la figura del ministerio fiscal y ello con independencia de que la víctima también se convierta en parte acusadora o se limite simplemente a declarar como mero testigo de lo sucedido. Por último, los delitos privados son aquéllos que sólo pueden perseguirse si la propia víctima denuncia los hechos y sostiene la acusación en el acto del juicio.

- La reforma llega con la Ley Orgánica 11/1999, de 30 de abril, de modificación del Título VIII del Libro II del Código Penal, aprobado por Ley Orgánica 10/1995, de 23 de noviembre.

10 Un tratamiento exhaustivo de esta cuestión puede encontrarse en FUENTES SORIANO, O., "La iniciación cuasi pública de los procesos por delitos sexuales" en "Derecho 
Para concluir con la forma de abordar en España ese segundo tipo de violencia de género a que hacía referencia la Declaración de Naciones Unidas de 1993 sobre "la eliminación de la violencia contra la mujer", sumamente importante resulta la desaparición del perdón de la víctima como causa extintiva de la responsabilidad criminal. Al marco general anteriormente descrito en el que el padecimiento de una agresión sexual era concebido por el Estado como una deshonra y la persecución del delincuente no se producía del modo en el que se reaccionaba frente a otros delincuentes comunes (ladrones, asesinos, estafadores...) -perseguidos por el Estado desde el momento en el que conocía la existencia del delito-, había que añadir escandalosa y lamentablemente que el perdón de la víctima de los delitos sexuales extinguía la responsabilidad criminal. Según ello, si durante la tramitación de un procedimiento judicial para perseguir, por ejemplo, la comisión de una violación, la víctima perdonaba al violador, el procedimiento terminaba y al violador no se le imponía pena alguna, puesto que ya no era criminalmente responsable: el hecho del perdón extinguía su responsabilidad criminal. En determinados ambientes sociales se llegó a situaciones en las que se comerciaba con el perdón y, así, un violador que se veía inmiscuido en un procedimiento judicial en el que se le iba a exigir responsabilidad, comerciaba con la víctima la cantidad económica que le tenía que pagar a cambio del perdón -dado que esta situación se producía en ambientes sociales humildes, el perdón y, con él, la impunidad resultaban ciertamente "baratos"-. Esta situación, por suerte superada en nuestro país, se mantiene todavía en muchos otros países en los que el perdón de la víctima sigue siendo objeto de compraventa o en los que sigue sin existir -como también sucedió en España- la violación dentro del matrimonio; es decir, países en los que el Estado sigue reconociendo el derecho del marido a mantener relaciones sexuales con su mujer siempre y en todo momento independientemente de la voluntad de ésta, de modo tal que si la fuerza a mantener relaciones sexuales contra su voluntad no comete delito alguno.

Como puede observarse a tenor del panorama descrito, el avance en España de la lucha frente a la violencia sexual contra la mujer ha sido importante y en consecuencia ha tenido importantes repercusiones. Hasta tal punto ha sido relevante el avance legislativo en la materia que, pese al hecho de que, como se ha explicado, el Derecho no es sino reflejo de la conciencia social -es decir, que el avance jurídico sucede con posterioridad al avance social-, en materia de lucha contra la agresión sexual no cabe admitir que España sea un país que, hoy, tolere ese tipo de violencia. Restan, sin embargo, dos grandes campos 
de "tolerancia estatal" "1 en relación con la violencia de género: la violencia intrafamiliar, por una parte, y la violencia, dentro de la comunidad, referida a las mafias de trata de mujeres para la prostitución por otra. No obstante, ciñéndonos exclusivamente a la violencia sexual contra la mujer y teniendo en cuenta las reformas legislativas anteriormente descritas, cabe llegar a afirmar que se ha dado solución al tercer problema determinante de la violencia de género según NU: el de la tolerancia de dicha violencia por parte del Estado.

El gran problema pendiente actualmente en España reside en la violencia de género intrafamiliar. Éste es parte del primero de los problemas destacados por la conferencia de UN de 1993 sobre eliminación de la violencia contra la mujer: la violencia (física, sexual y psicológica) producida en la familia, incluyéndose aquí no sólo los malos tratos sino también la violencia relacionada con la dote, la mutilación genital femenina o la violencia relacionada con la explotación.

Si bien es cierto que el problema de los malos tratos en el seno de la familia ni es único de España ni exclusivo del momento histórico que nos ha tocado vivir, es cierto, sin embargo, que asistimos en los últimos años a un alarmante incremento de la violencia de género en el seno de la familia; violencia de género a la que hay que sumar también -por tener similares características- la violencia ejercida contra los familiares más débiles como los niños y los ancianos y que se viene conociendo, en su conjunto, con el nombre de "violencia doméstica".

La violencia de género, también cuando se produce ésta en el seno de la familia, plantea el problema de su multidisciplinariedad. Y en consonancia con la multidisciplinariedad del problema se plantea también la de su solución. Son muchos los ámbitos y factores afectados (culturales, sociológicos, educacionales, religiosos, jurídicos...) y, por tanto, son muchos los elementos a tener en cuenta para hallar una posible solución.

Pese a que el presente estudio se centrará en los problemas jurídicos que plantea este tema, así como en las posibles soluciones -también jurídicas-a los mismos resultará conveniente hacer una importante referencia, dentro de las posibles vías de solución actualmente iniciadas, a los "protocolos de actuación" en materia de violencia de género. Tal y como enseguida se comprobará, los avances legislativos intentados por España en los últimos años han sido notables y dignos de

11 Entiéndase que cuando se habla de "tolerancia estatal" se utiliza el término en el sentido en el que se ha reproducido tras su utilización por parte de la conferencia de UN anteriormente referida. No se trata tanto de "grata tolerancia" ni de "complacencia" sino de búsqueda de soluciones que, en determinados casos como los que nos ocupan, todavía no se han encontrado. 
alabanza, pero sucede, sin embargo, que la práctica -la vida real- no sólo no se ha hecho eco de los mismos sino que el problema de la violencia de género intrafamiliar ha ido en aumento. Ante una situación como la descrita se pone obviamente de manifiesto la absoluta necesidad de intentar una actuación conjunta de los distintos grupos de profesionales implicados en la lucha contra este tipo de violencia: policía, personal sanitario, trabajadores sociales, jueces, fiscales, abogados..., $y$, en este sentido, han sido varias las provincias o CCAA (entre las cuales y desde fechas muy recientes cabe contar a la provincia de Alicante) que han elaborado protocolos o guías de actuación que marquen las pautas a seguir por los distintos profesionales implicados. ${ }^{12}$

Comenzaré el resto de este estudio por presentar la situación legislativa actualmente existente en España en materia de violencia de género.

La violencia de género en sentido amplio no está tipificada como tal en nuestro ordenamiento. Existen determinados tipos delictivos relativos a lesiones o agresiones físicas, psíquicas o sexuales contemplados con carácter general e independientemente de que sea hombre o mujer el sujeto activo o pasivo de la acción. Únicamente de forma específica se regula en el artículo 153 del Código Penal el delito conocido como de "malos tratos"; malos tratos cuya regulación se establece, también, de forma genérica e independientemente, por tanto, de que el autor de los mismos sea hombre o mujer (aunque estadísticamente es el varón en la práctica totalidad de los casos) y de que el sujeto pasivo o receptor de los malos tratos sea la mujer, los niños, los ancianos..., que conviven en el seno familiar.

El panorama legislativo actual es, pues, el siguiente:

- Faltas:

- Art. $617.1:^{13}$ lesiones; pena: arresto 3 a 6 fines de semana; multa de 1 a 2 meses.

- Art. 617.2: ${ }^{14}$ Maltrato de obra (no lesiona); pena: arresto 3 a 6 fines de semana; multa de 1 a 2 meses.

12 El problema de los malos tratos desde una perspectiva jurídica y los protocolos de actuación al respecto puede verse, con mayor detenimiento, en FUENTES SORIANO, O., "La reacción de la justicia ante los delitos de malos tratos", La mediación frente a la violencia: un desafio para el hombre y la mujer, Universidad de Alicante (en prensa).

13 Art. $617.1 \mathrm{Cp}$ : "El que, por cualquier medio o procedimiento, causare a otro una lesión no definida como delito en este Código, será castigado con la pena de arresto de tres a scis fines de semana o multa de uno a dos meses".

14 Art. 617.2 Cp: "El que golpeare o maltratare de obra a otro sin causarle lesión será castigado con la pena de arresto de uno a tres fines de semana o multa de diez a treinta días. Cuando el ofendido fuere alguna de las personas a las que se refiere el artículo 153, 
- Art. 620:15 Amenazas, coacciones, injurias y vejaciones leves; pena: multa 10 a 20 días.

\section{- Delito de malos tratos:}

- Art. 153.16

- Delitos sexuales: 178 a 183 Cp (se castigan con independencia de los posibles malos tratos).

Dado el carácter general que presentan los delitos y faltas de lesiones y dado que a las agresiones sexuales se ha hecho referencia con anterioridad conviene centrar la atención en el art. $153 \mathrm{Cp}$ regulador de los malos tratos.

El actual art. $153 \mathrm{Cp}$ procede del antiguo artículo $425 \mathrm{Cp}^{17}$ en relación con el cual se ha ampliado el grupo de los sujetos pasivos contra los cuales puede dirigirse la actuación violenta y, últimamente, tras la

la pena será la de arresto de tres a seis fines de semana o multa de uno a dos meses, teniendo en cuenta la posible repercusión económica que la pena impuesta pudiera tener sobre la propia víctima o sobre el conjunto de los integrantes de la unidad familiar".

15 Art. $620 \mathrm{Cp:} \mathrm{"Serán} \mathrm{castigados} \mathrm{con} \mathrm{la} \mathrm{pena} \mathrm{de} \mathrm{multa} \mathrm{de} \mathrm{diez} \mathrm{a} \mathrm{veinte} \mathrm{días:}$

$\left.1^{\circ}\right)$ Los que, de modo leve, amenacen a otro con armas u otros instrumentos peligrosos, o los saquen en riña, como no sea en justa defensa, y salvo que el hecho sea constitutivo de delito.

$\left.2^{\circ}\right)$ Los que causen a otro una amenaza, coacción, injuria o vejación injusta de carácter leve.

Los hechos descritos en los dos números anteriores sólo serán perseguibles mediante denuncia de la persona agraviada o de su representante legal.

Cuando el ofendido fuere alguna de las personas a las que se refiere el artículo 153, la pena será la de arresto de dos a cuatro fines de semana o la de multa de diez a veinte días, teniendo en cuenta la posible repercusión económica que la pena impuesta pudiera tener sobre la propia víctima o sobre el conjunto de los integrantes de la unidad familiar. En estos casos no será exigible la denuncia a que se refiere el párrafo anterior de este artículo, excepto para la persecución de las injurias".

16 Art. $153 \mathrm{CP}$. (Incluido en el Título III -De las lesiones-, del Libro II del CP): "El que habitualmente ejerza violencia física o psíquica sobre quien sea o haya sido su cónyuge o persona que esté o haya estado ligada a él de forma estable por análoga relación de afectividad o sobre los hijos propios o del cónyuge o conviviente, pupilos, ascendientes o incapaces que con él convivan o que se hallen sujetos a la potestad, tutela, curatela, acogimiento o guarda de hecho de uno u otro, será castigado con la pena de prisión de seis meses a tres años, sin perjuicio de las penas que pudieran corresponder a los delitos o faltas en que se hubieran concretado los actos de violencia física o psíquica.

17 El antiguo art. 425 al que se hace referencia fue introducido en el Cp por la L.O. 3/1989 de 21 de junio y castigaba a quien "habitualmente y con cualquier fin ejerza violencia física sobre su cónyuge o persona a la que estuviese unido por análoga relación de afectividad, así como sobre los hijos sujetos a la patria potestad, o pupilo, menor o incapaz sometido a su tutela o guarda de hecho, será castigado con la pena de arresto mayor". 
modificación de $1999,{ }^{18}$ contiene una referencia expresa a los malos tratos psicológicos. ${ }^{19}$

El primer rasgo que merece ser destacado del art. $153 \mathrm{Cp}$ es la expresa mención que realiza a dos clases de malos tratos: la violencia física y la violencia psíquica. Pero los malos tratos abarcan tres tipos de actuaciones violentas: físicas, psíquicas o sexuales. ${ }^{20}$ En consonancia con ello, si se quiere penar como malos tratos la violencia física o psíquica ejercida en el ámbito familiar habrá que acudir al art. 153. Y, aunque legalmente no existe un maltrato sexual regulado específicamente, para penar las agresiones sexuales producidas en el seno de la familia habrá que acudir a los delitos genéricos contra la libertad sexual, tipificados en los arts. 178 a $194 \mathrm{Cp}$. Ello no obstante, se producen en todo caso agravaciones de la pena prevista inicialmente con carácter general, para todos aquellos supuestos en los que la agresión sexual sucede en el ámbito familiar.

El segundo rasgo importante es el de la "habitualidad", es decir, la exigencia, para poder condenar por la vía del art. $153 \mathrm{Cp}$, de que el maltrato sea "habitual". Hasta la reforma de $1999^{21}$ la habitualidad exigida por el art. $153 \mathrm{Cp}$ era lo que se conoce como un "concepto jurídico indeterminado" quedando, por tanto, a manos de la jurisprudencia la determinación de lo que había que entender por "maltrato

18 El art. 153 Cp antes de la reforma del 99 (LO 14/1999 de 9 de junio) establecía que: "El que habitualmente ejerza violencia física sobre su cónyuge o persona a la que se halle ligado de forma estable por análoga relación de afectividad o sobre los hijos propios o del cónyuge o conviviente, pupilos, ascendientes o incapaces que con él convivan o que se hallen sujetos a la potestad, tutela, curatela o guarda de hecho de uno u otro, será castigado con la pena de prisión de seis meses a tres años, sin perjuicio de las penas que pudieran corresponder por el resultado que, en cada caso, se causare".

19 Un conciso resumen sobre la evolución legislativa del art. 153 Cp puede verse en la STS de 24 de junio de 2000. Núm. 927/2000; RJ $2000 \backslash 5792$.

20 El Consejo de Europa, no obstante, distingue -además de los tres tipos enumerados- los siguientes tipos de violencia doméstica: la violencia económica (desigualdad al acceso de los recursos compartidos), estructural (inclusión de barreras invisibles e intangibles en lo que a la realización de opciones o derechos básicos de las personas se refiere) y espiritual (obligación de adoptar un sistema de creencias culturales o religiosas determinado o erosión del sistema sostenido por la víctima). A mi juicio, sin embargo, estos últimos tres tipos de violencia doméstica son perfectamente subsumibles dentro de la violencia psíquica. Por otro lado esta interpretación favorece su posible penalización según nuestro sistema jurídico, pues, como se verá, el art. 153 Cp sólo se refiere a la violencia física o psíquica; de este modo, si consideramos que la violencia económica, estructural espiritual no se incluye en la violencia psíquica dejamos fuera de cobertura jurídica y sin posibilidad, por tanto, de penalizar todas estas actividades.

21 Modificación legislativa introducida en el Cp por el art. 2.1 ${ }^{\circ}$ de la LO 14/1999, de 9 de junio 
habitual" y con la gravedad de que si el maltrato no era considerado "habitual" la pena prevista en el art. 153 no se imponía al maltratador. Actualmente, la habitualidad viene definida en el art. 153.2 Cp en los siguientes términos: "para apreciar la habitualidad a que se refiere el párrafo anterior, se atenderá al número de actos de violencia que resulten acreditados, así como a la proximidad temporal de los mismos, con independencia de que dicha violencia se haya ejercido sobre la misma o diferentes víctimas de las comprendidas en este artículo, y de que los actos violentos hayan sido o no objeto de enjuiciamiento en procesos anteriores".

Como fácilmente puede observarse, se entiende la familia como un ente global y lo que se castiga es la violencia que se ejerza en su seno. Por ello se entenderá que el maltrato es habitual aunque se dirija la agresión frente a sujetos distintos; por ejemplo, un marido podría ser condenado por maltrato habitual aunque sólo hubiera golpeado una vez a su esposa si, en otras ocasiones, agredió a su hijo o a cualquier otro miembro de la familia. El problema más grave es el de la dificultad probatoria; obviamente, exige la Ley que tales agresiones hayan quedado "acreditadas": se supone, pues, que para obtener la condena del presunto agresor no bastará con la mera alegación de haber sido agredida. Encontrar soluciones a los problemas de prueba, según se verá posteriormente, es una de las claves del éxito en la persecución de la violencia de género. Si se facilita la fase probatoria se habrá ganado mucho en la lucha por erradicar este tipo de violencia. Téngase presente que la mayor parte de estos delitos (pero también otros propios de género como el acoso) por producirse en ámbitos estrictamente privados gozan de escasas posibilidades probatorias.

A modo de conclusión pues, para apreciar la "habitualidad" habrá que estar al caso concreto y ver cuántos actos violentos resultan acreditados. Si ya hubo denuncia y sentencia, por ejemplo, por lesiones, se podrán utilizar dichos hechos a efectos de constatar si hubo habitualidad. Últimamente, juzgados y tribunales parecen admitir que si hubo denuncia por lesiones pero se archivaron las actuaciones, o no se condenó por falta de prueba (porque - por ejemplo- la víctima no fue al juicio y se carecía de otros elementos probatorios que corroboraran su denuncia inicial...), dicha denuncia puede ser tenida en cuenta a efectos de observar la habitualidad. A este respecto (y al margen de que el art. 153.2 para apreciar la habitualidad exija "actos de violencia que resulten acreditados") conviene alertar sobre el riesgo de admitir meras denuncias no corroboradas como si, efectivamente, los hechos denunciados hubieran quedado probados. Indudablemente, los hechos que nos ocupan -los malos tratos- son, en muchos casos, hechos de difícil prueba. A ello se añade la situación de miedo y permanente contradic- 
ción en la que se desarrolla la vida cotidiana de las víctimas de este tipo de delitos y que les lleva, en multitud de ocasiones, a no comparecer el día del juicio, a no sostener la acusación, etc. Ello, sin embargo, no puede justificar la adopción con carácter general de medidas tales que lleven a dar por probado hechos que han sido, simplemente, denunciados. El éxito pues, estará en saber conjugar adecuadamente determinados criterios que tiendan a facilitar la prueba de las agresiones que se alegan, con la necesaria realidad que lleva a la imposibilidad de condenar si no es sobre la base de hechos que hayan quedado absoluta e indubitadamente probados (y recuérdese a estos efectos la máxima incuestionable que, en caso de duda, obliga a la absolución: in dubio pro reo). Por último, la habitualidad requiere también que los actos violentos no estén excesivamente alejados en el tiempo. Téngase presente que el elemento fundamental que viene exigiendo el Tribunal Supremo a efectos de discernir si hay o no habitualidad es que se cree una atmósfera o un clima de tensión en el seno de la familia. Ese ambiente tenso no se produce si no es tras una relativa continuidad en las agresiones.

El tercer y último elemento a destacar del art. $153 \mathrm{Cp}$, regulador de los malos tratos en el seno de la familia, es el relativo al sistema de penas que instaura: a la pena prevista por la comisión del delito descrito (pena de prisión de seis meses a tres años) hay que añadir la pena que corresponda al agresor por la comisión del delito concreto de que se trate (por ejemplo: lesiones, homicidio en grado de tentativa...) así como la posible adopción - por un plazo máximo de hasta cinco años- de alguna de las prohibiciones recogidas en el art. $57 \mathrm{Cp}-$ a) prohibición de aproximarse a la víctima o a aquéllos de sus familiares $u$ otras personas que determine el juez, b) prohibición de comunicarse con la víctima o con aquéllos de sus familiares u otras personas que determines el juez y c) prohibición de volver al lugar en el que se haya cometido el delito o de acudir a aquél en el que resida la víctima o su familia, si fueren distintos-.

La mejoría legislativa experimentada, pues, en materia de malos tratos (en los que se incluye la violencia de género producida en el seno de la familia) ha sido sin duda notable; especialmente, si a la situación descrita unimos la importante reforma llevada a cabo en materia de medidas cautelares ${ }^{22}$. El resultado de esta mejora debiera, sin duda,

22 En 1999 se introduce en la Ley de Enjuiciamiento Criminal un art. 544 bis a tenor del cual se establecen las posibles medidas cautelares a adoptar judicialmente en la investigación de supuestos delictivos incluidos en el art. $57 \mathrm{Cp}$ (entre otros, la práctica totalidad de los supuestos de violencia doméstica). Entre dichas medidas se encuentran las siguientes: a) prohibición de residir en un determinado lugar, b) prohibición de acudir a determinados lugares, c) prohibición de aproximarse o comunicarse a determinadas 
haber aportado un resultado exitoso y, sin embargo, nos encontramos, precisamente, en la situación contraria pues, tal y como se sostenía al principio de el presente estudio, la situación delictiva a este respecto ha experimentado un notable recrudecimiento. Una de las razones del fracaso de las innovaciones legislativas reside, posiblemente, en el absoluto olvido de la figura de la víctima en el momento de abordar las reformas. Tal y como se ha tenido ocasión de ver, asistimos en los últimos años a una importante mejoría en la redacción de los tipos penales, se han incrementado las penas e incluso se han introducido nuevas posibilidades de condena y prohibiciones para los agresores, se ha establecido una nueva regulación de medidas cautelares conveniente, sin duda, para la marcha del proceso, sin embargo, se ha hecho absoluta abstracción, por parte del legislador, de la difícil situación psicológica por la que atraviesan las víctimas de violencia doméstica o incluso las víctimas de agresiones sexuales independientemente de que las agresiones se produzcan o no en el seno de la familia.

Directamente relacionado con lo anterior, debe tenerse presente que la tramitación de cualquier procedimiento judicial genera en la víctima el fenómeno que se conoce como de "victimización secundaria". Se entiende por victimización secundaria la experiencia negativa que sufre la víctima de un delito (el padecimiento del propio delito genera la victimización primaria) como consecuencia de la toma de contacto con el aparato burocrático del Estado a fin de conseguir la persecución del mismo: largas colas para denunciar, trato deshumanizado por parte de personal no especializado, reiteración -en muchos casos innecesariade diligencias policiales, judiciales, etc. ${ }^{23} \mathrm{~A}$ todos estos datos hay que

personas y d) para el caso de incumplimiento de las anteriores medidas prevé el mencionado artículo la posibilidad de adoptar "nuevas medidas cautelares que impliquen mayor limitación de su libertad personal", en clara referencia a la posibilidad de acordar la prisión provisional.

Sobre este tema puede verse COMPTE MASSACHS, T., "Medidas de protección en cl Estado Español", en CD Violencia de género. Legislación de los paises de la Unión Europea, Proyecto DAPHNE. Proteger, Asociación de mujeres juristas Themis.

23 A juicio de GARCÍA BECEDAS, la victimización secundaria "se refiere a las relaciones que surgen entre la víctima y el sistema jurídico-penal, en definitiva, con el aparato del Estado, la Policía, la Administración de Justicia, etc.; y es precisamente esta experiencia la que en muchas ocasiones resulta más negativa para la víctima pues, normalmente, el hecho victimizador le ha introducido en un mundo desconocido, donde se habla en un lenguaje que le es absolutamente incomprensible (...), donde sucesivos funcionarios les aturden con múltiples explicaciones y peticiones de datos, donde no se les permite desahogarse y se les atiende en algunos casos con rechazo incluso (...), donde en suma, la burocratización del sistema les anula". Vid. GARCÍA BECEDAS, Ma José, "La victimología como ciencia y su transposición a la realidad a través de las oficinas de ayuda a las víctimas de los delitos (O.A.V.D.)" La Ley, $n^{\circ}$ 4906, 15 de octubre de 1999 , pp. 1 a 5, (la cita es de p.2). En el mismo sentido puede verse MONTERDE FERRER, 
añadir el hecho de que la recepción de todo tipo de información, así como de material documental (declaraciones policiales de la víctima, levantamiento de atestados por parte de la policía, informe médico sobre la agresión...) en las primeras fases de la puesta en marcha de un procedimiento judicial, es de total trascendencia a efectos probatorios y de investigación de los hechos y, por tanto, cualquier fallo en su recepción o custodia, que impida su posible empleo posterior a efectos probatorios, supone el fracaso del procedimiento y la desconfianza, no sólo de la víctima, sino de toda la sociedad, en el sistema judicial instaurado.

Precisamente con la finalidad de intentar evitar -en la medida de lo posible- la victimización secundaria y de homogeneizar procedimentos y dirigir a los distintos colectivos de profesionales implicados instrucciones precisas a fin de que sus actuaciones se realicen de forma correcta para y con la víctima y el ulterior procedimiento judicial que se tramite, se han elaborado en distintas provincias y CCAA guías o protocolos de actuación a seguir por dichos profesionales cuando se enfrenten a supuestos de violencia de género experimentada por la mujer.

En marzo de 2002 se presentó en Alicante una "guía para profesionales ante el maltrato e informativa para mujeres maltratadas" 24 en la que se unifican criterios y se marcan las pautas que se deben seguir a nivel del personal sanitario, de los trabajadores sociales, a nivel judicial, etc.

Para un correcto tratamiento de la víctima y del problema en cada momento por el que atraviesa el mismo, se analizan en la guía tres fases diferentes: 1) la fase previa o de acceso a la Administración de la mujer que sufre el maltrato, 2) la fase en que la Administración judicial adopta soluciones inmediatas al problema planteado por la mujer maltratada y 3) la fase de vigilancia de las medidas acordadas con anterioridad. De estas tres fases (todas ellas anteriores al momento de dictar sentencia), sin duda la primera presenta un carácter de mayor mutidisciplinariedad. La actuación conjunta y coordinada de los distintos sec-

F., "Victimología. Proyecciones asistenciales prácticas", Cuadernos de Derecho Judicial, CGPJ, Madrid, 1993.

24 Esta guía (¿Qué debe hacer una mujer maltratada ante una agresión?. Guía para profesionales ante el maltrato e informativa para mujeres maltratadas. Manual práctico para unificar la actuación multidisciplinar en la lucha contra la violencia doméstica, Ed. Bancaja, 2002) ha sido coordinada por el Presidente de la Audiencia Provincial de Alicante, D. Vicente Magro Servet, y en ella se recoge el trabajo conjunto de jueces, abogados, procuradores, médicos, psiquiatras, personal de centros penitenciarios y de la administración de justicia, miembros de las fuerzas y cuerpos de seguridad del Estado, psicólogos, trabajadores sociales... 
tores de profesionales se intenta sobre la base de la puesta en práctica de determinados protocolos que se especifican en la guía. Para la actuación en la primera fase reseñada se han preparado los siguientes protocolos: protocolo de asistencia sanitaria, protocolo de denuncia ante el juzgado, protocolo de denuncia ante la comisaría y la guardia civil así como medidas de intervención policial inmediata, protocolo de escrito interesando la adopción de medidas previas a la demanda de separación matrimonial (distinguiendo los supuestos de matrimonio de los de las parejas de hecho y, dentro de éstos, distinguiendo si hay o no hay hijos), protocolo de auto adoptando medidas cautelares, y por último se señalan vías y pautas de actuación para los supuestos de detección de malos tratos, ya sea en vía sanitaria, policial, en Centros Mujer 24 horas, en los Servicios Sociales de los Ayuntamientos, en la oficina de atención a las víctimas del delito, en los servicios de orientación jurídica o en las fiscalías.

Según se establece en la propia guía, con la puesta en marcha de todos estos protocolos se persiguen los siguientes cinco objetivos: ${ }^{25}$

1. Unificar los criterios de actuación de los agentes actuantes frente a la violencia de género, así como el uso estadístico de los datos recibidos.

2. Diseñar y compartir los indicadores de evaluación.

3. Dotar al personal de la posibilidad de detectar indicadores de una violencia no declarada por parte de la víctima.

4. Garantizar la coordinación permanente entre las áreas afectadas.

5. Tener un conocimiento preciso de la dimensión de la violencia de género en el municipio y sensibilizar a la opinión pública sobre el alcance y magnitud del problema, divulgando servicios y recursos existentes.

Si bien es cierto que, como se dijo anteriormente, la victimización secundaria se da en todo tipo de delitos por la mera tramitación del procedimiento, la especial situación en la que se encuentran las víctimas de violencia de género requiere de un tratamiento individualizado. Normalmente, las mujeres víctimas de malos tratos tenderán a ocultar la procedencia de las lesiones, modificarán su declaración, tratarán de evitar su comparecencia en el acto del juicio oral... Por tanto, es frecuente la reacción -consciente o inconscente-que les lleva a ocultar o modificar cualquier elemento que, en principio, se presente como determinantemente probatorio. De ahí la relevancia de que los atestados policiales, los partes sanitarios, las tomas de declaración...sean exhaustivas y se centren en aquellos extremos que, verdaderamente, 
puedan tener relevancia probatoria en el juicio que ulteriormente se celebre.

A tal fin, se establece en el protocolo sanitario la necesidad de recoger los síntomas y signos más habituales de maltrato doméstico así como unas pautas de actuación para el personal sanitario cuando la paciente sugiera ser víctima de malos tratos ${ }^{26}$. En dicho protocolo se recoge de forma reglada toda la información concerniente a las lesiones físicas y psíquicas relacionadas con el maltrato, la necesidad de tratamiento, la incapacidad laboral si se aprecia, etc. Y, por supuesto, se recoge el mecanismo para poner dicha información en conocimiento judicial. La clave del éxito de esta nueva forma de tramitación coordinada de las investigaciones por malos tratos reside en el éxito en las vías de comunicación judicial de los distintos pasos que se vayan dando en cada nivel.

A nivel policial, se reconoce la necesidad de hacer un esfuerzo para tratar de integrar y coordinar las actuaciones de la policía local, nacional y de la guardia civil a fin, entre otras cosas, de favorecer el seguimiento de las medidas que se adopten. Se establecen determinadas pautas de comportamiento policial cuando la intervención se produce en el lugar de los hechos ${ }^{27}$, se establece también la necesidad de una "atención de emergencia" consistente en ofrecer a las víctimas de violencia doméstica un trato preferente y respetuoso (posibilitando las denuncias en despachos en los que se garantice la privacidad) así como una información integral y asesoramiento de urgencia en torno a sus

26 Según se sosticne en la propia guía, "el protocolo sanitario tiene como objeto fijar pautas de actuación común para los profesionales sanitarios ante situaciones de malos tratos, tanto físicos como psíquicos, y agresiones sexuales. Así, la primera actuación del personal sanitario scrá prestar una correcta atención a los posibles daños y lesiones físicas y psíquicas de la víctima que acude a la consuita y, en segundo lugar, cumplimentar adecuadamente el parte de lesiones, ya que se convierte en una prueba fundamental para la calificación del hecho como delito o falta". Vid. ¿Qué debe hacer...?, op. cit., p. 56.

27 Se tendrán en consideración los siguientes elementos: a) el derecho fundamental a la inviolabilidad del domicilio, b) se procurará la mayor separación física posible entre el agresor y la víctima, c) se tratará de procurar una sensación de calma y seguridad a la víctima, d) se realizará una inspección ocular del lugar que se hará constar por escrito reflejando de manera detallada la descripción de todos aquellos vestigios que pudieran contribuir al esclarecimiento de los hechos, e) incautación del instrumento con el que se hubiera producido la agresión, como pieza de convicción, f) localización y citación para declarar, de los posibles testigos -directos o indirectos- de los hechos, g) invitación a la víctima a acompañarla a las dependencias policiales al objeto de poder reflexionar y tomar decisiones con mayor libertad, h) si la víctima no quisiera denunciar, la propia policía interpondrá la denuncia e i) en caso de lesiones se acompañará a la víctima a un centro sanitario donde se le ofrezca la atención necesaria y se cmita el correspondiente parte de lesiones que se adjuntará a la denuncia a efectos probatorios. Vid. a este respecto ¿Qué debe...?, op. cit., pp. 73-74. 
derechos, recursos existentes y posibilidad de adopción de medidas concretas, indicando cuál es la de mayor pertinencia en función del supuesto concreto. ${ }^{28}$

Por último, para aquellos supuestos en que la mujer agredida acuda directamente a los servicio sociales, las pautas de actuación fijadas en el protocolo son las siguientes: si requiere asistencia sanitaria por presentar lesiones, se procederá a la derivación de la mujer a un centro sanitario que actuará de conformidad con lo previsto en el protocolo de actuación sanitaria; si, por el contrario, la mujer no requiere asistencia sanitaria se actuará de acuerdo con las siguientes pautas: a) se le proporcionará una atención adecuada informándole de los derechos que le asisten así como de los recursos existentes para atender sus necesidades, b) se le informará de su derecho a denunciar ante la policía o ante el juzgado, para lo cual, se le acompañará en caso necesario, c) siempre y en todo caso se derivará a la mujer a un psicólogo o a un psiquitra de la red de salud para que evalúe su estado emocional, d) en todo caso se cumplimentará el protocolo del servicio que se presenta en la guía al objeto de conocer y analizar el grado de violencia ejercido contra ella -téngase presente la dificultad de investigar sobre el maltrato cuando no hay signos obvios de lesiones-. ${ }^{29}$

Todas estas medidas contenidas en los distintos protocolos de actuación y esbozadas aquí muy a grandes rasgos contribuirán, sin duda, a mitigar los perniciosos efectos de la victimización secundaria. Sin embargo, y a modo de valoración final, plantean el inconveniente de ser, fundamentalmente, voluntaristas y de no tener carácter general. Recuérdese que se trata de protocolos elaborados tan sólo en determinadas provincias o CCAA y que no tienen ninguna fuerza vinculante quedando su cumplimiento a la buena voluntad (dependiente -en muchos casos- del grado de comprensión del problema) de quienes hayan de aplicarlos. El futuro legislativo habrá de pasar, posiblemente, por

28 "Nos encontramos [se sostiene en la guía] ante una situación especial, en la que se entremezclan sentimientos complejos y contradictorios entre el agresor y la víctima. Es necesario, por ello, que los funcionarios policiales conozcan la importancia de favorecer un adecuado acogimiento en el primer contacto que se tiene con las víctimas, favoreciendo una atención basada en la escucha, comprensión y refuerzo de la decisión tomada (evitar la "victimización secundaria"), comprendiendo la complejidad de la dependencia emocional que presentan las víctimas, que, incluso, pueden limitar su colaboración con los agentes policiales, y que en ocasiones pueden llevarlas a retirar la denuncia. Las Fucrzas y Cuerpos de Seguridad del Estado deben tener una "sensibilización especial y una perfecta formación" para no juzgar estas acciones, y deberían mostrar siempre la misma atención e interés aunque la víctima haya retirado más de una vez la denuncia (Rellenar siempre el parte de denuncia)": Vid ¿Qué debe hacer...?, op. cit., p. 72 .

29 Vid. ¿Qué debe hacer...?, op. cit., p. 90. 
una Ley integral en materia de violencia doméstica ${ }^{30}$ que recoja medidas tan necesarias como la especialización de los juzgados, la aplicación a las víctimas de este tipo de delitos de las medidas especiales previstas en la Ley de protección de testigos y peritos en causas criminales, la posibilidad de llevar a cabo determinadas diligencias instructoras a modo de prueba anticipada para evitar la posterior -y en muchos casos innecesaria-reiteración en el acto del juicio oral, una regulación sistemática de la presencia efectiva del Ministerio Fiscal y de sus posibilidades de actuación en esta materia, la tramitación de estos procedimientos como juicios rápidos, el total y absoluto conocimiento por parte de la víctima del estado en que se encuentra el procedimiento judicial, etc.

\section{BIBLIOGRAFÍA.}

COMPTE MASSACHS, T.: "Medidas de protección en el Estado español", en CD Violencia de género. Legislación de los países de la Unión Europea, Proyecto DAPHNE. Proteger, Asociación de mujeres juristas Themis.

FUENTES SORIANO, O.: "La valoración de la prueba indiciaria y la declaración de la víctima en los delitos sexuales", Problemas actuales de la administración de justicia en los delitos sexuales, Defensoría del Pueblo, Perú, Lima, 2000.

FUENTES SORIANO, O.: "La iniciación cuasi pública de los procesos por delitos sexuales" en "Derecho penal y discriminación de la mujer. Anuario de Derecho Penal 1999-2000", 2001.

FUENTES SORIANO, O.: "La reacción de la justicia ante los delitos de malos tratos", La mediación frente a la violencia: un desafío para el hombre y la mujer, Universidad de Alicante (en prensa).

GARCÍA BECEDAS, $M^{a}$ J.: "La victimología como ciencia y su transposición a la realidad a través de las oficinas de ayuda a las víctimas de los delitos (O.A.V.D.)" La Ley, ñ 4906, 15 de octubre de 1999.

MAGRO SERVET, V:: "Propuestas para una reforma legal integral en materia de violencia doméstica", La Ley, jueves 21 de diciembre de 2000.

MONTERDE FERRER, F: "Victimología. Proyecciones asistenciales prácticas", Cuadernos de Derecho Judicial, CGPJ, Madrid, 1993.

PÉREZ DEL CAMPO, A.M.: "Recursos para la recuperación integral de las víctimas de la Violencia de Género" en Primeras jornadas sobre violencia de género. Aspectos Técnicos y judiciales, Ajuntament de Sant Joan d'Alacant, mayo 2001, pp. 23 a 52; p. cit. 25.

30 A este respecto vid., MAGRO SERVET, V., "Propuestas para una reforma legal integral en materia de violencia doméstica", La Ley, jueves 21 de diciembre de 2000 . 
VV.AA.: Guía de buenas prácticas y usos forenses para combatir la violencia de género. Asociación de mujeres juristas Themis, 2001.

VV.AA.: ¿Qué debe hacer una mujer maltratada ante una agresión?. Guía para profesionales ante el maltrato e informativa para mujeres maltratadas. Manual práctico para unificar la actuación multidisciplinar en la lucha contra la violencia doméstica. Ed. Bancaja, 2002. 